\title{
Role of the sea anemone Metridium senile in structuring a developing subtidal fouling community
}

\author{
Matthew L. Nelson, Sean F. Craig* \\ Department of Biology, Humboldt State University, 1 Harpst St. Arcata, California 95521, USA
}

\begin{abstract}
In a variety of ecological settings, individual species have been shown to possess the ability to influence the structure and development of the community at large. However, within fouling communities, the influences of many sessile invertebrate species and how they drive patterns of succession remain relatively unexplored. The sea anemone Metridium senile is ubiquitous in cold temperate fouling communities, but its role within these communities has largely been overlooked. Natural fouling communities that had formed on plastic experimental panels were 'gardened' to form treatments containing only $M$. senile, compound ascidians, or erect bryozoans. These panels were deployed under floating docks and were surveyed photographically over $4 \mathrm{mo}$. M. senile maintained more free space through time within its experimental treatment community than did organisms contained within the other 2 (ascidian or bryozoan) treatments. Subsequent short-term field experiments on recruitment concluded that the presence of $M$. senile in fact enhances recruitment rates among fouling organisms (relative to controls), ruling out larval predation and larval avoidance as a cause for observed long-term patterns. However, when $M$. senile were placed upon panels containing natural recruitment in laboratory tanks, it was shown that the anemone 'smothers' the majority of these new recruits by sliding over them with its pedal disk, killing all other potential space occupiers and thereby generating increased free space. This study illustrates how a single species can have multiple, opposing influences on patterns of succession at different temporal scales.
\end{abstract}

KEY WORDS: Fouling community $\cdot$ Metridium senile $\cdot$ Recruitment $\cdot$ Succession Resale or republication not permitted without written consent of the publisher

\section{INTRODUCTION}

Marine fouling communities contain, inter alia, sessile filter feeding invertebrates (solitary and colonial), which occur subtidally on hard substrates such as ship hulls, docks, pilings, and boulders. While succession has been classically described from terrestrial systems as an orderly and directional process resulting in a stable climax community (Odum 1969), many long-term, multi-year studies within fouling communities have illustrated cyclical and seasonal patterns of settlement, recruitment, growth, and senescence with no stable climax community being reached (e.g. Boyd 1972, Sutherland \& Karlson 1977). These processes of succession can generate ecological patterns within fouling communities as each organism reproduces, grows and dies in seasonal cycles that can vary between species.
These long-term studies also show high variability in patterns of succession across space and time. It is this variability, inherent in fouling communities, that has often generated inconsistent results and conflicting conclusions in previous studies of successional processes and the role of individual species in generating pattern (e.g. settlement: Grosberg 1981, Bullard et al. 2004; species richness, free space, and invasion: Stachowicz et al. 2002, Dunstan \& Johnson 2004). This variability has often caused more focus on the pattern itself rather than on the underlying processes which cause these patterns.

It has been suggested that the mechanisms that affect succession are invoked by interactions between individual species (Breitburg 1985) and are based on the traits of these species (Underwood \& Anderson 1994). Numerous studies have debated the importance 
of various factors, including settlement (Chalmer 1982), recruitment (Underwood \& Anderson 1994), growth and competition (Buss \& Jackson 1979, reviewed by Buss 1986), predation (Osman \& Whitlatch 2004, Nydam \& Stachowicz 2007), disturbance (Altman \& Whitlatch 2007), and other abiotic factors (such as temperature: McCarthy et al. 2007, Osman \& Whitlatch 2007) in causing the observed patterns of succession within fouling communities. Thus, the way in which individual species interact with each other, and with the environment around them, plays a crucial role in determining the resulting community structure.

Previous studies have shown that by manipulating natural communities to include or exclude the subject species, it is possible to elucidate the mechanisms by which individuals structure the community at large. Through removal experiments, Sutherland (1978) showed that the presence of the bryozoan Schizoporella unicornis and the ascidian Styela plicata led to the formation of previously observed 'multiple stable points' during succession (Sutherland 1974). Similarly, Blum et al. (2007) showed that the presence of the invasive ascidian Ciona intestinalis dominated space and depressed species richness, while Davis \& Ward (2009) showed that the presence of the barnacle Austrobalanus imperator is essential in the formation of a species rich community by promoting the recruitment of other sessile invertebrates. Still other studies have used addition and removal experiments to demonstrate lowered diversity by the blue mussel Mytilus edulis (Durr \& Wahl 2004), recruitment facilitation among the ascidians Pyura spinifera and Cnemidocarpa pedata (Davis 1996), and reduced settlement due to the presence of 4 different species of resident ascidians (Osman \& Whitlatch 1995). Nevertheless, the specific mechanisms by which many species of common fouling organisms influence their neighbors, and how these mechanisms alter the community at large, remain relatively unexplored.

The present study focuses on the anthozoan Metridium senile and how adult anemones affect early successional processes within the first 4 mo of a developing fouling community. $M$. senile, found in cold temperate waters across the northern hemisphere, is a conspicuous member of these invertebrate communities. Despite its cosmopolitan distribution and abundance, few studies (Whomersley \& Picken 2003) have examined the role that anemones play in influencing patterns of succession and development within fouling and other subtidal marine communities. Casual observation underneath floating docks in Humboldt Bay (Eureka, California, USA) reveals dense aggregations of M. senile. Previous data (S. Craig \& D. Janiak unpubl. data) suggests that these aggregations may persist for several months or longer, creating a stable point within the community similar to those observed by Sutherland $(1974,1978)$. However, the mechanisms by which $M$. senile comes to dominate space and affect patterns of succession in the surrounding community when present as adults have not been explored.

Aside from the universal cnidarian trait of stinging nematocysts, Metridium senile also possesses a suite of other traits that may make it a superior spatial competitor among sessile fouling organisms. M. senile can reproduce asexually through both pedal laceration and longitudinal fission (Chia 1976), and although M. senile is largely considered a sessile organism, it has the capacity for slow locomotion by sliding along the substrate on its pedal disk. Additionally, adult $M$. senile have shown the ability to detach from the substrate and drift up to several kilometers to recolonize previously depopulated areas (Wahl 1985). Together, clonal growth and locomotion may allow $M$. senile to be more successful than other sessile invertebrates at colonizing small patches of open space as they arise (Anthony \& Svane 1995).

Metridium senile is also a voracious predator of planktonic larvae. Feeding by $M$. senile on nauplius larvae in the laboratory was recorded at rates up to 700 larvae polyp ${ }^{-1} \mathrm{~min}^{-1}$ (Anthony 1997), and in the field, a single individual was recorded eating nearly 200 ascidian tadpole larvae and 100 barnacle cyprid larvae in a single day (Sebens \& Koehl 1984). It has been suggested that such intense feeding behavior may effectively prevent settlement onto adjacent substrata (Jackson 1979, Sebens \& Koehl 1984, Young 1988).

Additionally, Metridium senile may have the potential to kill newly recruited larvae, even after they have successfully settled and metamorphosed, by sliding their pedal disk over new recruits as the anemone moves about. Dissolved oxygen beneath the pedal disk of $M$. senile was measured consistently at zero, while the $\mathrm{pH}$ was measured as low as 4.45 (Woolmington \& Davenport 1983). The anemones' pedal disk thus creates potentially deadly conditions for newly recruited sessile invertebrates as $M$. senile slides over and smothers them.

Finally, previous studies have shown that the larvae of common fouling organisms may avoid settling next to superior spatial competitors by delaying metamorphosis (Young \& Chia 1981), or simply settling elsewhere (Grosberg 1981). If Metridium senile pose a significant threat to free-swimming larvae or new recruits, it is possible that larvae may avoid settling in areas occupied by this anemone.

To summarize, Metridium senile has the potential to be a dominant spatial competitor and strong structuring force within fouling communities by rapidly colonizing bare substrata, consuming free-swimming larvae 
before they can recruit, killing new recruits by smothering them underneath their pedal disks, and/or repelling recruits that actively avoid settling near them. This study first illustrates patterns of increased freespace generated by $M$. senile during a 4 mo study of early succession in a marine fouling community. Subsequent experiments then test for the following 3 mechanisms as plausible means by which $M$. senile generates the observed patterns of free space: (1) larval predation: the reduction of recruitment due to consumption of larvae by $M$. senile before they have a chance to settle; (2) larval avoidance: the reduction of settlement due to larval avoidance of areas near $M$. senile; (3) recruit 'smothering': the death of new recruits caused by movement of $M$. senile over the top of these recruits, smothering them with their pedal disk. Additionally, because the physical structure of resident fouling organisms can affect recruitment patterns (e.g. Dean 1981, reviewed by Koehl 2007), the effect of the physical shape of $M$. senile on recruitment was evaluated. By creating individual experiments in order to test for the specific mechanism(s) by which $M$. senile generated the initially observed patterns of free space, a better understanding of which traits caused these patterns of community development can be attained.

\section{MATERIALS AND METHODS}

Field experiments were conducted beneath the floating docks at Woodley Island Marina, Eureka, California, USA $\left(40^{\circ} 48^{\prime} \mathrm{N}, 124^{\circ} 09^{\prime} \mathrm{W}\right)$. These docks are situated in the northern part of Humboldt Bay away from its mouth, protected from waves and other open-ocean conditions. Acrylonitrile butadiene styrene (ABS) plastic panels $(10 \times 15 \mathrm{~cm})$ were suspended at $\sim 1 \mathrm{~m}$ depth below the floating docks upon racks created from polyvinyl chloride (PVC) piping (Fig. 1). Panels were attached to racks using a single 1/4 inch, phillips-head bolt through the center of the panel with the experimental surface of the panel facing downward. All panels were evenly spaced among each of 3 PVC racks, and these racks were placed directly next to each other underneath the dock, exposing them to similar environmental conditions. Suspended panels were completely shadowed by the floating dock above them at all times, allowing for the examination of interactions between invertebrates without the influence of algal growth. The floating docks at Woodley Island Marina are 28 yr old and used year-round, making them a permanent fixture within Humboldt Bay.
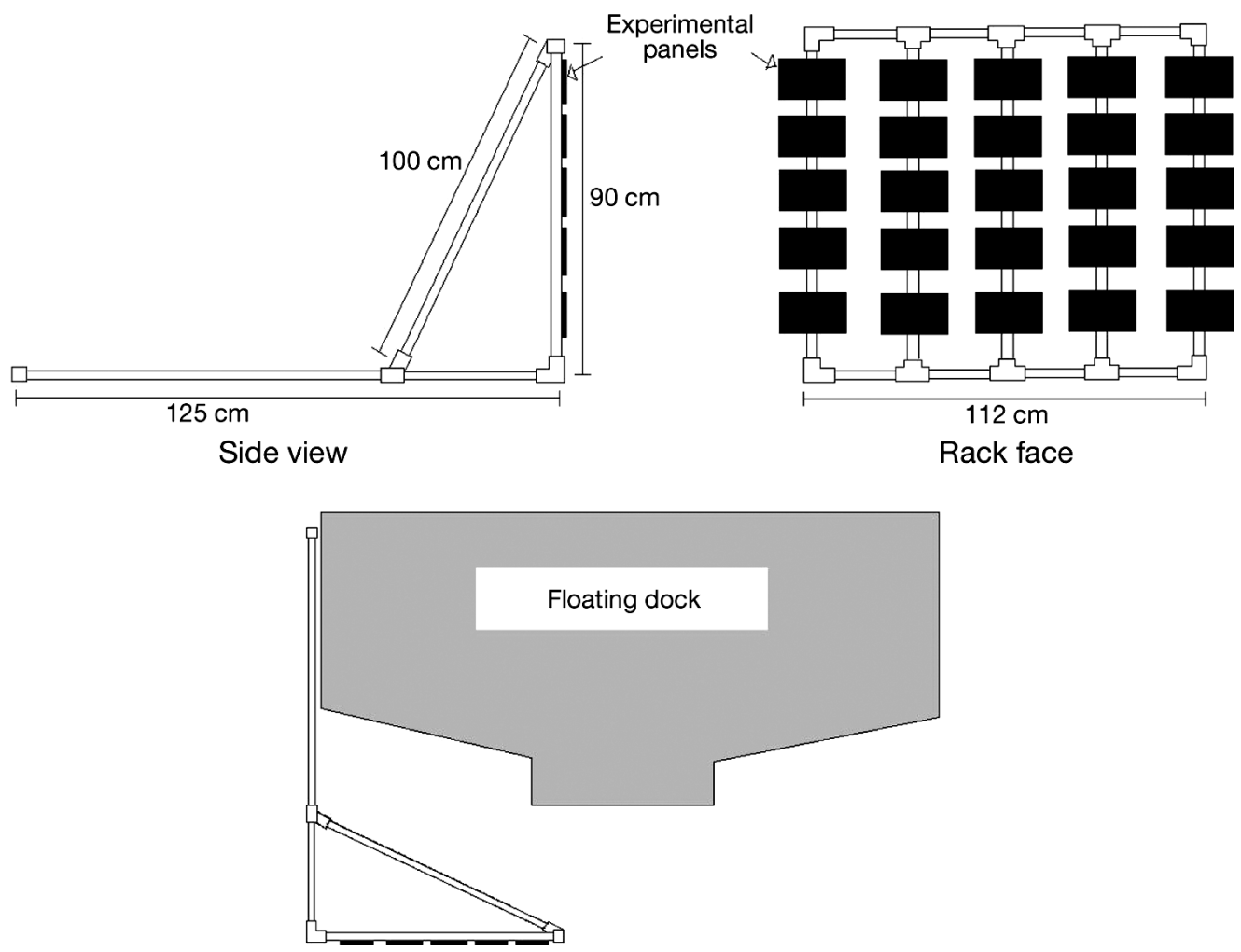

Rack deployed under floating dock

Fig. 1. Side and end-view of the design and deployment of one of the PVC racks used in this experiment to hold 25 black acrylonitrile butadiene styrene (ABS) plastic experimental panels $(10 \times 15 \mathrm{~cm})$. Relative position of the rack when deployed under the floating dock at Woodley Island Marina, Eureka, CA, is also shown. All diagrams are not drawn to scale 
Laboratory experiments were conducted at Humboldt State University's Telonicher Marine Laboratory in Trinidad, California, in shallow flowing-seawater tables which received filtered seawater directly from Trinidad Harbor.

The Metridium senile used in all experiments possessed pedal disks which ranged from 1 to $4 \mathrm{~cm}$ in diameter, a size typical of $M$. senile found in Humboldt Bay fouling communities.

Monthly successional patterns. Patterns of succession including the amount of free space and organism cover were observed as fouling communities developed naturally upon experimental panels. These panels were grouped into treatments which initially contained Metridium senile or treatments which initially contained other common fouling organisms, to determine if patterns of community development differed depending on the initial sessile marine invertebrates present. Later experiments were used to determine the mechanisms which drive these patterns.

Experimental panels containing mature $(>1 \mathrm{yr}$ of development) fouling communities were 'selectively gardened' (e.g. Perrett et al. 2006) to a particular treatment where all panels contained 20 to $25 \%$ coverage of the one desired organism or growth form, and 75 to $80 \%$ free uncolonized space. Each of the treatments below were comprised of organisms with growth morphologies as defined by Jackson (1979), which are among the most common fouling organism morphologies found in Humboldt Bay. The 3 treatments established held either (1) the anemone Metridium senile $(\mathrm{n}=4)$; (2) a combination of the compound ascidians Botryllus schlosseri and Botrylloides sp. $(\mathrm{n}=5)$; or $(3)$ a combination of the erect bryozoans Bugula neritina, B. californica, and Scrupocellaria diagensis $(\mathrm{n}=3)$. The use of the later 2 treatments is used here to illustrate how other fouling organisms may have an effect on patterns of succession in comparison to those of M. senile. By 'gardening' natural communities, we attempted to establish more realistic spatial arrangements and maintain the relative positions of the study organisms within their communities. This 'selective gardening' also imitates natural disturbance which may be caused by seasonal death and 'sloughing' of sessile organisms (Sutherland \& Karlson 1977), or through the predation (Nydam \& Stachowicz 2007) or 'bulldozing' (Meece et al. 2006) of the chiton Mopalia $\mathrm{sp}$. The natural recovery of each treatment community was then followed through time. A fourth Blank treatment contained panels in which all resident organisms were removed to create $100 \%$ free space and were used to assess community development without the influence of established residents. By scraping clean panels with previously developed communities, any bio-films or bacteria that may have been present on treatment panels should also be present on Blank panels, which is important because these films can strongly affect recruitment (reviewed by Scheltema 1974, Wieczorek \& Todd 1997).

Individual panels could not be placed randomly on each PVC rack below the docks because certain organisms from one treatment could move or grow onto an adjacent panel with a different treatment, altering the panels' initially intended composition. For example, individual anemones have the potential to move onto neighboring panels intended to contain only compound ascidians or erect bryozoans. Additionally, compound ascidians may grow off their experimental panel and onto an adjacent one, potentially changing a nearby treatment. Nevertheless, PVC racks were randomly located in a new position under the dock approximately every week. This served to randomize any micro-spatial effects of having a given treatment panel in a given location under the dock. In doing this, each panel should not be influenced by any consistent differences in flow rate, larval supply, or other abiotic factors that may exist in different spatial areas underneath the floating docks at the Woodley Island Marina.

Panels were deployed on 22 September 2007 and were surveyed via digital photography (Hewlett Packard M425 camera, 5.0 megapixel resolution) approximately every 4 wk. The experiment ended on 14 January 2008 when it was determined that the majority of the original organisms used to establish each of the initial treatments had senesced. All image analysis was done using Adobe Photoshop software. Percent cover on each panel was estimated by laying a 96 -point $(12 \times 8)$ grid over panel photos and the organisms (or free space) present at each point was counted and represented as a percent of the total area of the panel.

Percent data were square root and arcsine transformed to meet the assumptions of normality and the amount of free space on the experimental panels was compared among treatments and through time with a repeated-measures ANOVA using NCSS 2007 statistical software. Data from the Blank treatment were not included in this analysis because this treatment contained a higher percentage of initial free space than organism-containing treatments, and was therefore not comparable. This initial difference in free space would have generated a significant difference between treatments that would represent an artifact of the experimental setup, and not a comparison of the effects of the initial composition of residents. Nevertheless, data from the Blank treatment are represented graphically along with the other treatments in Fig. 3 to illustrate the rate at which unoccupied space is colonized without the initial influence of resident adult organisms. 
Short-term effects of Metridium senile. Field experiments: The first 2 potential mechanisms, larval predation and larval avoidance, were tested in the field. To test for larval predation by $M$. senile, anemones were placed onto experimental panels $(\mathrm{n}=10)$ in densities that approximated those on the long-term succession panels (20 to $25 \%$ coverage). If these anemones feed on free swimming larvae, recruitment could be reduced because larvae are consumed before they contact the panel surface and metamorphose.

It is also possible that larvae may avoid these Anemone panels due to chemical detection of Metridium, followed by behavioral changes in swimming direction, which would also lower recruitment. By comparing panels containing live anemones to panels testing exclusively for larval avoidance, it is possible to determine whether larval avoidance, larval predation, or both are operating to reduce recruitment.

To test for larval avoidance of anemones, large anemones Metridium senile were removed from the floating docks and their pedal disks were rubbed across the surface of a set of bare experimental panels to coat these panels with copious amounts of mucus exuded by the anemone. In this way, the panels in this Mucus treatment $(n=10)$ may contain the chemical scent of anemones, and therefore potentially be detected and avoided by swimming larvae as they test the surface of the panel for appropriate settlement cues. Although there was no re-application of mucus during the experiment, in laboratory tanks, strands of mucus were seen to persist in the water without dissolving for $>24 \mathrm{~h}$ (authors' pers. obs.). Blank panels ( $\mathrm{n}=19)$ were untreated experimental panels scraped completely clean in a similar manner to those in the succession monitoring experiment to retain any bacterial or algal films present. These Blank panels were used to determine the maximum amount of recruitment expected without anemones present.

Panels were evenly spaced and secured on 4 smaller PVC racks (each holding 10 panels) and suspended adjacent to each other in a manner similar to the previous experiment that monitored for patterns of community development. Panels containing Metridium senile were once again grouped so that wandering anemones could not move onto other treatments because these were deployed on other racks. Experimental panels were exposed to natural recruitment for a period of $3 \mathrm{~d}$ (7 to 10 July 2008).

An additional short-term field experiment was conducted (22 to 26 August 2008) to assess the physical effects of
Metridium senile on recruitment because the physical structure created by many resident fouling organisms may alter flow and, thus, recruitment of some organisms (reviewed by Koehl 2007). M. senile mimics were used to recreate the structure of living anemones and alter flow without the movement or feeding patterns typical of the live anemones. Mimics were constructed of both small plastic 'monster toys' $(\sim 3.5 \mathrm{~cm}$ high and $2 \mathrm{~cm}$ across) and the rubber hemispheres from 'bouncy balls', which were cut in $2(\sim 3 \mathrm{~cm}$ across $)$. Both items were secured to panels using a 2-part epoxy gel adhesive to create 20 to $25 \%$ cover (Fig. 2). The shape of the 'monster toys' roughly mimicked the shape of a feeding anemone with its oral disk and tentacles extended into the water column. The rubber hemispheres mimicked the shape of an anemone that had pulled in on itself in defense. This mimic experiment consisted of 3 treatments: (1) an Anemone treatment ( $\mathrm{n}=6$ ) containing panels with 20 to $25 \%$ coverage of live M. senile, (2) a Mimic treatment $(\mathrm{n}=7)$ containing panels with 20 to $25 \%$ coverage of fake anemones in both feeding and retracted positions, and (3) a Blank treatment $(\mathrm{n}=10)$ containing panels with no living adult organisms or artificial structure of any kind. Experimental panels were exposed to natural recruitment for a period of $4 \mathrm{~d}$ (22 to 25 August 2008).

Panels were surveyed using digital photography (Canon Powershot A590 IS, 8.0 megapixel resolution) at the conclusion of the experiment. Recruitment was expressed as the density of organisms (recruits $\mathrm{cm}^{-2}$ ) rather than counts, because areas occupied by Metridium senile were not available for larval recruitment. To calculate the area of available free space on panels containing anemones, the percent of the panel not occupied by anemones was estimated by using a 96-

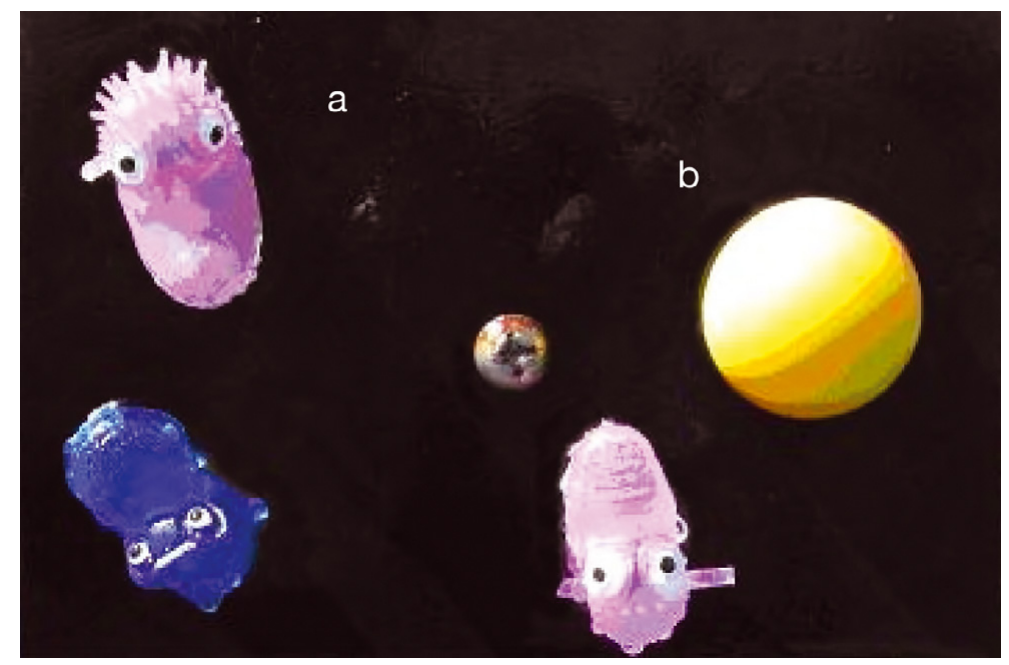

Fig. 2. Mimic field experiment. Physical mimics of Metridium senile using small plastic children's toys that approximate the shapes of either an (a) outstretched or (b) pulled-in sea anemone 
point grid in the manner described above and this percent free space was then multiplied by the total area of the experimental panel $\left(150 \mathrm{~cm}^{2}\right)$. Data were compared using a Kruskal-Wallis test because not all data were normally distributed. Multiple pair-wise comparisons of treatment categories were made using Mann-Whitney $U$-tests with $\alpha$ reduced to 0.0167 via Bonferroni correction. Statistical analysis was done using Minitab 13 software.

Laboratory experiments: The third potential mechanism for the generation of free space by sea anemones, the smothering of recruits beneath an anemones' pedal disk, was examined in the laboratory. In the field, 19 blank panels were subjected to natural larval recruitment for $6 \mathrm{~d}$ at the Woodley Island Marina. These panels were then transported in tubs of seawater to shallow seawater tables in the laboratory, where they were haphazardly assigned to either a Control or an Anemone treatment. Panels in the Anemone treatment $(\mathrm{n}=10)$ had Metridium senile gently placed on them to approximate the $25 \%$ coverage used in field experiments. Control panels $(n=9)$ were left alone, bearing natural recruits acquired in the field. Panels sat overnight to allow for the attachment of anemones before the start of the experiment.

Both Control and Anemone treatments were bolted to identical racks constructed from PVC piping with the experimental surface facing down and placed in adjacent water tables. The racks held each panel only a few millimeters under the surface of the water to prevent anemones from sliding around the back of the panels and off the experimental surface (Metridium senile preferred to remain under water). Each day, all panels were briefly removed from their tanks $(<3 \mathrm{~min})$ while photographs of Anemone treatment panels were taken to track the movements of $M$. senile. This was done not to quantify distance traveled, but rather to roughly estimate the path traveled by anemones each day. By estimating the path of each anemone, the status of recruits caught in an anemones' path could be compared to those that did not come into contact with an anemone. While distance moved was not quantified in the experiment, $M$. senile in laboratory holding tanks were seen on occasion to move up to $30 \mathrm{~cm} \mathrm{~d}^{-1}$ (authors' pers. obs.). Also, each day both treatments were fed with a half gallon of a mixture of the phytoplankters Isochrysis sp. and Tetraselmis sp. poured into each water table, and flow was shut off for $1 \mathrm{~h}$ while they were feeding. Mortality due to anemone feeding was not expected as recruits were already established on the panels prior to the addition of anemones.

At the start of the laboratory experiment, panels were examined under a dissecting microscope to count the number of living recruits upon each panel and to assess any recruits that were already dead (from overnight exposure to anemones or natural mortality). These dead recruits were not included in any subsequent analyses. After $5 \mathrm{~d}$, all recruits remaining alive were counted under a dissecting microscope. Recruits of the compound ascidians Botryllus schlosseri and Botrylloides sp. were marked as dead if no flow of blood could be seen while examining their vascular canals. The compound ascidians Distaplia occidentalis and Diplosoma macdonaldi, the solitary ascidian Molgula manhattensis, and the bryozoan Alcyonidium sp., all had tissues that quickly deteriorated upon death, making them easy to recognize as dead if they had not already disappeared from the panel entirely. The bryozoans Watersipora subtortorquata and Celleporella hyalina, along with the calcareous tube-building polychaete worm Spirorbis sp., all had delicate calcareous parts that became visibly damaged and discolored upon death. Barnacles were marked as dead if only the test remained. Colonial animals were counted as dead when all zooids within the colony were deceased. A colony that contained at least one functional zooid was counted as living, as that single living zooid still had the potential for colonial growth and may have regenerated the colony.

Densities of live recruits at the beginning and end of the experiment were calculated in a similar manner to the field experiment above. The difference between beginning and ending densities on each panel was calculated as the proportion of recruits remaining alive. If Metridium senile was harmful to recruits, one would expect a greater proportion of recruits remaining alive in the Control treatment than in the Anemone treatment. The proportion of recruits remaining alive in each treatment was compared using a MannWhitney $U$-test in Minitab 13.

\section{RESULTS}

\section{Monthly successional patterns}

The community development upon experimental panels containing either the anemone Metridium senile, compound ascidians, or erect bryozoans was monitored for $\sim 4$ mo. The results of a repeatedmeasures ANOVA showed that the amount of free space within these experimental communities varied significantly with treatment, time, and their interaction term, with the Anemone treatment maintaining the most free space though time (Fig. 3, Table 1). Although the Blank treatment was not used in the analysis, the amount of cover by fouling organisms on these panels eventually surpassed that on the Anemone treatment. Free space within the Compound ascidian, Erect bryozoan, and Blank treatments all fell towards zero 


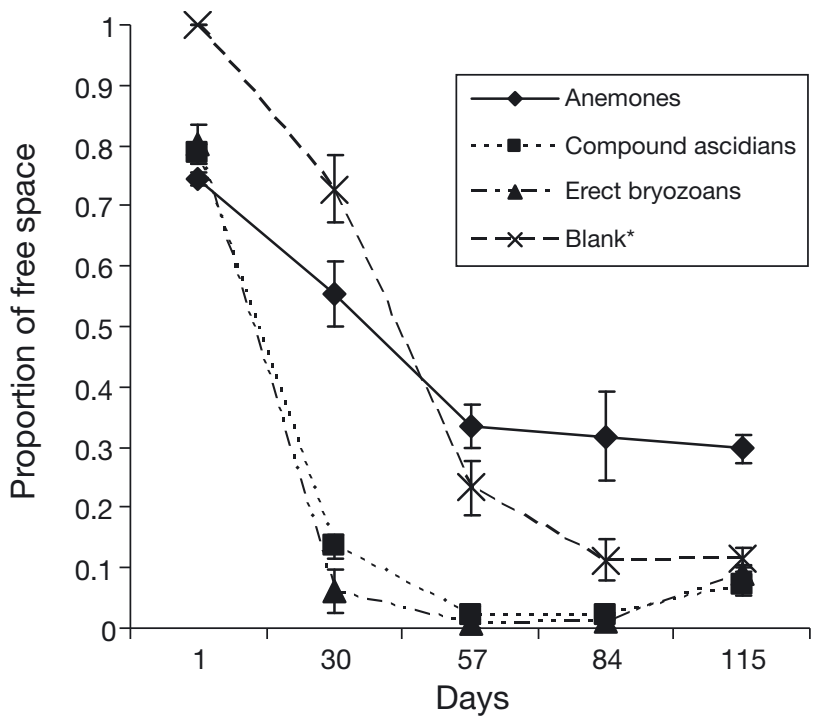

Fig. 3. Effect of Anemones, Compound ascidians, Erect bryozoans, and Blank panels on free space through time. Mean proportion $( \pm \mathrm{SE})$ amount of unoccupied space within each treatment through time. ${ }^{*}$ Blank treatment was not used in the statistical analysis as it contained more initial free space than other treatments, but is shown here so patterns of free space can be compared

within 2 to 3 mo. Free space within the organism-containing treatments did not differ significantly at the onset of the experiment $(F=2.21$, df $=2, \mathrm{p}>0.05$, 1-way ANOVA).

\section{Short-term field experiments}

Experimental panels of the Anemone, Mucus, and Blank treatments were exposed to $3 \mathrm{~d}$ of natural recruitment. The density of recruits varied significantly among Anemone, Mucus, and Blank treatments in this $3 \mathrm{~d}$ field experiment (Fig. 4; $H=25.32$, p $<0.001$, Kruskal-Wallis). Pair-wise comparisons between individual treatments using Mann-Whitney $U$-tests ( $\alpha$ adjusted to 0.0167 via Bonferroni correction) revealed (1) significantly higher recruitment density on the

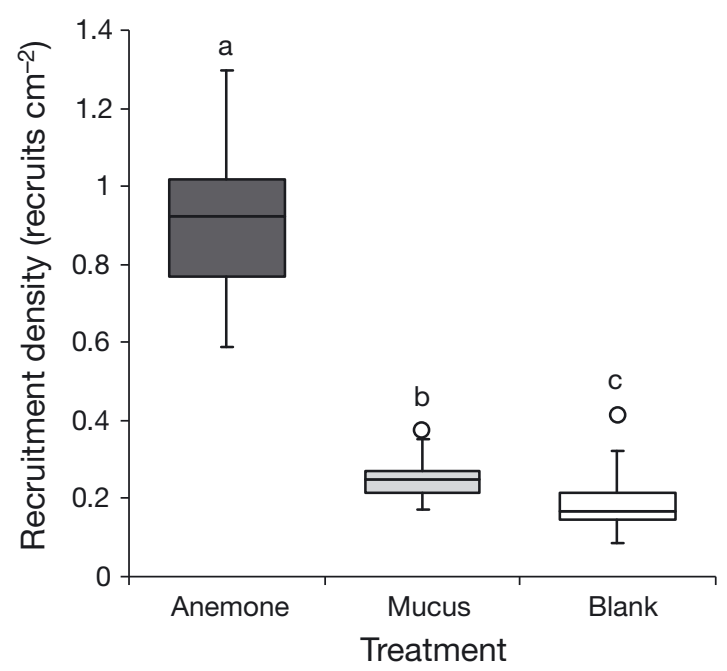

Fig. 4. Median, interquartile, and the non-outlier range of recruitment densities upon Anemone, Mucus, and Blank treatments after being exposed to natural recruitment in the field for $3 \mathrm{~d}$. Whiskers: 1.5 interquartile range from the 3rd and 1st quartile. Circles: outliers. Pair-wise comparisons were made using Mann-Whitney $U$-tests with $\alpha$ adjusted via Bonferroni correction. Bars with different letters are significantly different from one another $(\mathrm{p}<0.0167)$

Anemone treatment than on Blank ( $U=245.0$, p < 0.001); (2) significantly higher recruitment density on the Mucus treatment than on Blank $(U=205.0, \mathrm{p}=$ 0.012); (3) significantly higher recruitment density on the Anemone treatment than on the Mucus treatment $(U=155.0, \mathrm{p}<0.001)$.

When assessing the effects of the physical structure of Metridium senile on recruitment, both living anemones and physical mimics clearly influenced larval recruitment (Fig. 5; $H=18.69$, df $=2$, p $<0.001$; Kruskal-Wallis). Pair-wise comparisons revealed that recruitment densities were highest on panels containing live anemones, with Mimic panels containing the second highest recruitment densities, and Blank containing the lowest recruitment densities (MannWhitney $U$-test, $\mathrm{p}<0.017, \alpha$ adjusted via Bonferroni correction).
Table 1. Results from a repeated-measures analysis of variance of available free space within the (1) Metridium senile, (2) Compound ascidian, and (3) Erect bryozoan treatments through time. ${ }^{*}$ Significant $p$-value

\begin{tabular}{|lccccc|}
\hline Source & df & SS & MS & F-ratio & p-value \\
\hline Treatment & 2 & 1.69 & 0.85 & 40.44 & $<<0.001^{*}$ \\
Error (between) & 9 & 0.19 & 0.02 & & \\
Time & 4 & 5.39 & 1.35 & 262.20 & $<<0.001^{*}$ \\
Treatment $\times$ Time & 8 & 0.70 & 0.09 & 17.08 & $<<0.001^{*}$ \\
Error (within) & 36 & 0.18 & 0.01 & & \\
Total (adjusted) & 59 & 8.31 & & & \\
Total & 60 & & & & \\
\hline
\end{tabular}

\section{Short-term laboratory experiments}

After new recruits on experimental panels were obtained in the field, recruits were exposed to either Metridium senile or ambient tank conditions in the laboratory for $5 \mathrm{~d}$. The Control treatment had a significantly higher proportion of recruits surviving than Anemone panels to which the sea anemone $M$. senile were added (Fig. 6A; $U=135.0, p<0.001$, Mann- 


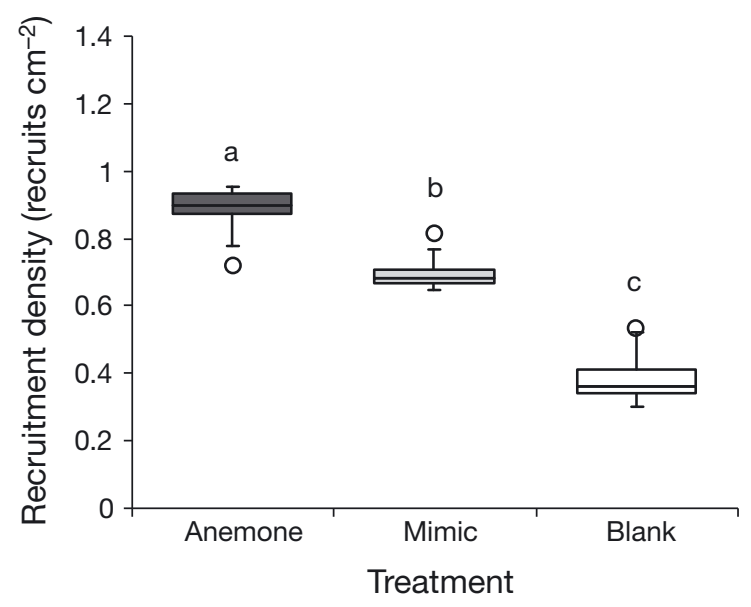

Fig. 5. Mimic field experiment: median, interquartile, and the non-outlier range of recruitment densities upon Anemone $(\mathrm{n}=6)$, Mimic $(\mathrm{n}=7)$, and Blank $(\mathrm{n}=10)$ treatments exposed to $4 \mathrm{~d}$ of natural recruitment. See Fig. 4 for defintions and explanation of statistics
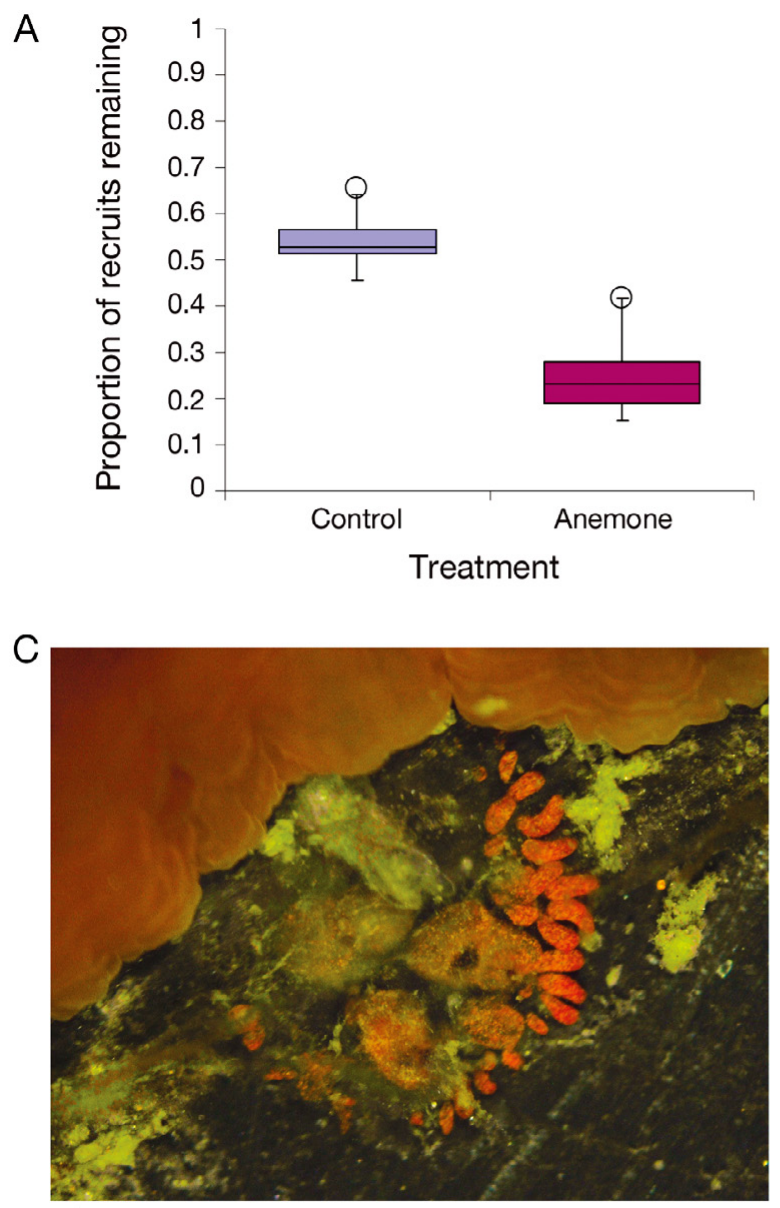

Whitney $U$-test). Fig. 6B to D shows photographs of newly dead tunicate colonies after an individual anemone slid over them with their pedal disk, leaving colonies containing no functional zooids. Every observed instance of an anemone sliding over a recruit resulted in the death of the affected organisms.

\section{DISCUSSION}

This study shows that full-grown specimens of the sea anemone Metridium senile can have major effects on the patterns of fouling community development within Humboldt Bay during the first few months of succession, with the anemone first enhancing recruitment rates and then subsequently decreasing recruit survival creating an overall negative effect. Treatments in the long-term experiment began with similar amounts of free space, but by the end of the 4 mo monitoring period, panels with $M$. senile contained
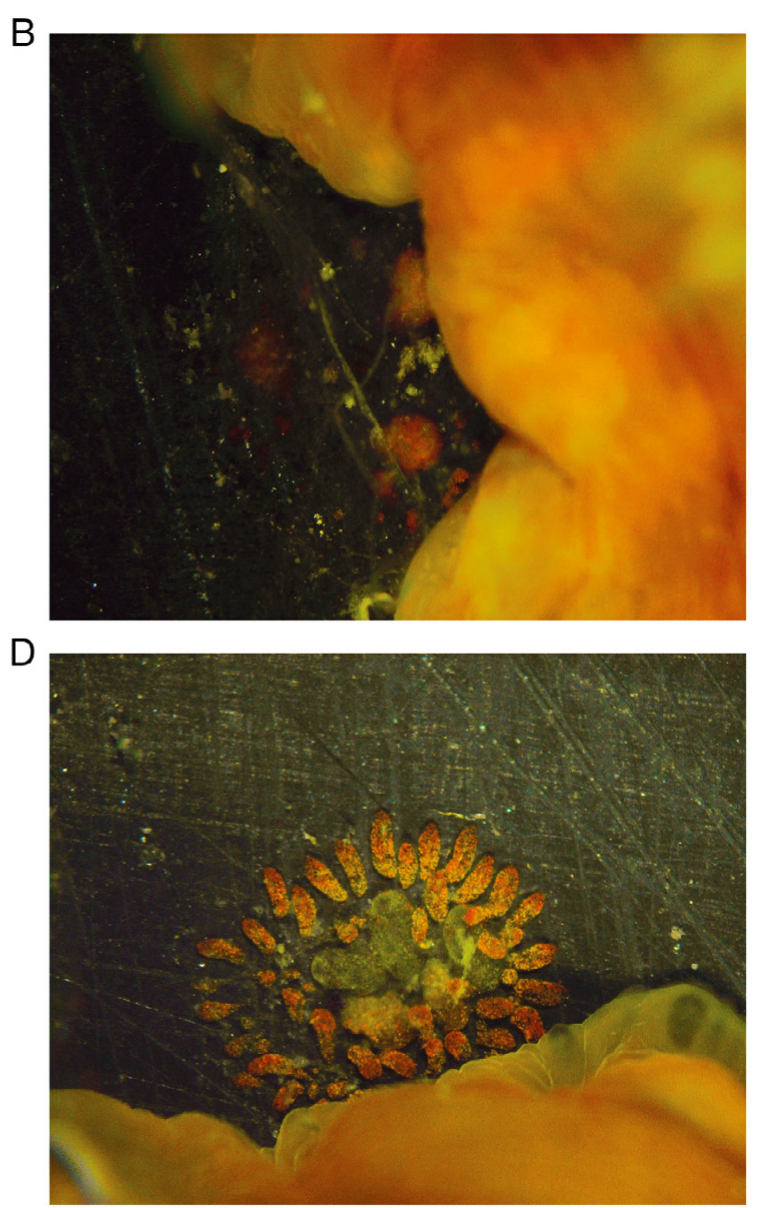

Fig. 6. New recruits exposed to Metridium senile. (A) Median, interquartile, and non-outlier range of the proportion of recruits remaining alive on panels after exposure to $M$. senile for $5 \mathrm{~d}$ in the laboratory (Mann-Whitney $U$-test, $U=135.0, \mathrm{p}=0.0003$ ) relative to Control panels, which lacked anemones. Whiskers: 1.5 interquartile range from the 3rd and 1st quartile. Circles: outliers. (B to D) Photographs from a dissecting microscope showing edge of different $M$. senile anemones with their pedal disk sliding off a now deceased tunicate Botrylloides sp. colony 
$\sim 3$ times more unoccupied space than panels in the other 3 treatments $(29.7 \%$ on Anemone panels versus 9.2\% averaged across other treatments; Fig. 3). The cause for this pattern was then explored through subsequent short-term experiments in the field and laboratory, which tested several possible mechanisms by which this sea anemone may have generated the observed trend. The results of the field experiments ruled out larval predation and larval avoidance as an explanation for the observed patterns of succession, at least during the summer months when these experiments took place (Fig. 4). This conclusion is due to the enhanced recruitment observed in the presence of anemones, rather than the decrease in recruitment that would be expected if predation or larval avoidance had occurred.

However, laboratory experiments show that as Metridium senile slowly moves across a surface on its pedal disk, any new recruits unfortunate enough to be caught underneath are 'smothered' and killed (Fig. 6). Recruit death is possibly due to the stressful conditions of extremely low $\mathrm{pH}$ and near-zero dissolved oxygen underneath their pedal disks (Woolmington \& Davenport 1983). This process allows $M$. senile to clear the surrounding substrate of potential spatial competitors and continue dominating space within these communities, thus explaining initially observed long-term patterns of the maintenance of free space through time. As long as they are able to keep moving, these anemones can maintain a large amount of free space.

Short-term field experiments showed that Metridium senile does not consume enough larvae to decrease recruitment rates at all times, despite results from previous studies which showed high larval predation rates by this anemone in both the field and the laboratory (Sebens \& Koehl 1984, Anthony 1997). A similarly small effect on settlement through larval predation was seen in studies focusing on several solitary ascidians (Young 1989), where the effects of predation were swamped by a large number of recruiting larvae, even though high levels of larval predation were observed in the laboratory. Similarly, the short-term field experiments presented here were conducted during the peak summer recruitment of fouling organisms. It is likely that the effects of larval predation by anemones were swamped by high levels of larval recruitment. Nevertheless, the possibility remains that larval predation by $M$. senile may be an important factor in determining recruitment rates during seasons with lower recruitment pressure in fouling communities.

The short-term results also show that free-swimming larvae do not avoid the presence of Metridium senile. Anemone panels generated recruitment densities which were far greater than those found in the Mucus and Blank treatment panels (Fig. 4). Additionally, the
Mucus treatment generated higher recruitment densities than did the Blank treatment. While it is tempting to conclude that there may be some sort of enhancement effect on recruitment by the anemones' mucus, the difference seen in recruitment densities upon the Mucus and Blank panels is more likely only a statistical difference created by largely unequal sample sizes, and may not be ecologically relevant.

Despite generating patterns of increased free space in the long-term by killing new recruits, Metridium senile generated increased recruitment of fouling organisms (colonization of space) in the short-term. Although the presence of live $M$. senile generated significantly higher recruitment densities than did anemone mimics, both of these treatments generated greater levels of recruitment than blank panels (Fig. 5). This result suggests that the physical structure created by the anemones' presence enhances recruitment by virtue of its disruption of the boundary layer flow across these panels, and may in part explain previous findings of increased recruitment around $M$. senile. This finding is not surprising given that slower water velocities and lower drag forces have been found within aggregations of $M$. senile (Koehl 1977). Additionally, many previous studies have shown enhanced settlement due to turbulent flow created by resident benthic organisms and other elements of surface rugosity (e.g. Wethey 1986, Havenhand \& Svane 1991, Harvey \& Bourget 1997), which can lead to the passive deposition of larvae on settlement surfaces (reviewed by Koehl 2007).

The overall effect of Metridium senile on the structure of fouling communities is similar to that of chiton grazers (e.g. Mopalia sp.) in that both of these organisms generate increased amounts of free space within the community. While the movements of $M$. senile cause the death of fouling organisms by 'smothering' new recruits, grazing (Nydam \& Stachowicz 2007) and movements of the chiton Mopalia sp. (Meece et al. 2006) generates a 'bulldozing' effect as fouling organisms are scraped off the substrate. In the case of Mopalia sp., it appears that certain organisms, such as barnacles, may have a size escape where larger individuals are no longer in danger of removal by chitons (S. Craig \& D. Janiak unpub. data). It remains unclear whether larger fouling organisms can escape the deleterious effects of $M$. senile as well.

The dominant influence of Metridium senile on this subtidal fouling community occurred over several months, with the creation of free space caused by the movements of $M$. senile and the smothering of new recruits. Conversely, over the shorter time scale of several days, the presence of $M$. senile created a surprising pattern (given initial observations), where increased recruitment was seen. Different traits pos- 
sessed by this single species thus have opposite effects upon the community depending on the length and timing of observations, with the long-term effects of M. senile counteracting those of the short-term. It is therefore possible that one organism can have multiple influences on succession because of the different ways in which it interacts with the surrounding community at different points in time and during different successional processes.

Because the initial observations of the effects of Metridium senile on a developing community were aimed at viewing overall trends, and were thus made on a monthly basis, the other mechanisms by which anemones can affect the community were not detected as they operate on a shorter temporal scale. Alternatively, if the effects of $M$. senile on recruitment had been the sole topic of study, logic follows that the results would have generated a very different conclusion: that $M$. senile enhances the rate at which free space is colonized, leading to a fouling community which is largely covered by many different sessile invertebrates and has very little uncolonized space. By evaluating both the short and long-term influences of $M$. senile across different temporal scales, this study shows that post-recruitment mortality generated by the movements of $M$. senile nullifies the short-term influence of enhanced recruitment, which may be created at least in part by the anemones' physical structure.

In light of these findings, it is suggested that when evaluating patterns of succession, it is important to examine multiple traits of an individual species and their effects on the community across multiple time scales. This approach may lead to a better understanding of the processes generating the ever-shifting mosaic of sessile invertebrates within marine fouling communities.

Acknowledgements. We thank the 4 anonymous reviewers for their constructive comments, which improved the manuscript greatly, and the staff and management of Humboldt State University's Telonicher Marine Laboratory in Trinidad, CA, USA, for providing flowing seawater facilities and technical assistance. In addition, we thank the following faculty, staff, and students from Humboldt State University for their advice and support: M. J. Boyd, M. Rizzardi, T. Mulligan, M. Camann, M. Mesler, H. Carson, A. Young, G. Eberle, D. Hoskins, E. Wilson, J. Koeppel, R. Koeppel, J. Adams, G. Jones, B. Spirou, and B. Bridegroom. This research was supported in part by NSF grant DBI-0755466 to S.F.C., as well as a Gary G. Brusca Award for Invertebrate Zoology and a Malcolm Oliphant Marine Science Scholarship at Humboldt State University to M.L.N.

\section{LITERATURE CITED}

Altman S, Whitlatch RB (2007) Effects of small-scale disturbance on invasion success in marine communities. J Exp Mar Biol Ecol 342:15-29
Anthony KRN (1997) Prey capture by the sea anemone Metridium senile (L.): effects of body size, flow regime, and upstream neighbors. Biol Bull (Woods Hole) 192: $73-86$

Anthony KRN, Svane I (1995) Effects of substratum instability on locomotion and pedal laceration in Metridium senile (Anthozoa: Actiniaria). Mar Ecol Prog Ser 124:171-180

Blum JC, Chang AL, Liljesthrom M, Schenk ME, Steinberg MK, Ruiz GM (2007) The non-native solitary ascidian Ciona intestinalis (L.) depresses species richness. J Exp Mar Biol Ecol 342:5-14

Boyd MJ (1972) Fouling community structure and development in Bodega Harbor, California. PhD thesis, University of California, Davis, CA

Breitburg DL (1985) Development of a subtidal epibenthic community: factors effecting species composition and the mechanisms of succession. Oecologia 65:173-184

Bullard SG, Whitlatch RB, Osman RW (2004) Checking the landing zone: Do invertebrate larvae avoid settling near superior spatial competitors? Mar Ecol Prog Ser 280: 239-247

Buss LW (1986) Competition and community organization on hard surfaces in the sea. In: Diamond J, Case TJ (eds) Community ecology. Harper \& Row, New York, NY, p $517-536$

Buss LW, Jackson JBC (1979) Competitive networks: nontransitive competitive relationships in cryptic coral reef environments. Am Nat 113:223-234

Chalmer PN (1982) Settlement patterns of species in marine fouling communities and some mechanisms of succession. J Exp Mar Biol Ecol 58:73-85

Chia F (1976) Sea anemone reproduction: patterns and adaptive radiations. In: Mackie G (ed) Coelenterate ecology and behavior. Plenum Press, New York, NY, p 261-270

Davis AR (1996) Association among ascidians: facilitation of recruitment in Pyura spinifera. Mar Biol 126:35-41

> Davis AR, Ward DW (2009) Establishment and persistence of species-rich patches in a species-poor landscape: role of a structure-forming subtidal barnacle. Mar Ecol Prog Ser 380:187-198

> Dean TA (1981) Structural aspects of sessile invertebrates as organizing forces in an estuarine fouling community. J Exp Mar Biol Ecol 53:163-180

> Dunstan PK, Johnson CR (2004) Invasion rates increase with species richness in a marine epibenthic community by two mechanisms. Oecologia 138:285-292

> Durr S, Wahl M (2004) Isolated and combined impacts of blue mussels (Mytilus edulis) and barnacles (Balanus improvisus) on structure and diversity of a fouling community. J Exp Mar Biol Ecol 306:181-195

Grosberg RK (1981) Competitive ability influences habitat choice in marine invertebrates. Nature 290:700-702

> Harvey M, Bourget E (1997) Recruitment of marine invertebrates onto arborescent epibentic structures: active and passive processes acting at different spatial scales. Mar Ecol Prog Ser 153:203-215

> Havenhand JN, Svane I (1991) Roles of hydrodynamics and larval behavior in determining spatial aggregation in the tunicate Ciona intestinalis. Mar Ecol Prog Ser 68:271-276

Jackson JBC (1979) Morphological strategies of sessile animals. In: Larwood G, Rosen BR (eds) Biology and systematics of colonial organisms. Academic Press, London, p 499-555

Koehl MAR (1977) Effects of sea anemones on the flow forces they encounter. J Exp Biol 69:87-105

Koehl MAR (2007) Mini review: hydrodynamics of larval settlement into fouling communities. Biofouling 23:357-368 
McCarthy A, Osman RW, Whitlatch RB (2007) Effects of temperature on growth rates of colonial ascidians: a comparison of Didemnum sp. to Botryllus schlosseri and Botrylloides violaceus. J Exp Mar Biol Ecol 342:172-174

Meece SL, Craig SF, Janiak D (2006) The role of the chiton Mopalia ciliata in the creation and maintenance of free space within marine fouling communities. Integr Comp Biol 46:E230

Nydam M, Stachowicz JJ (2007) Predator effects on fouling community development. Mar Ecol Prog Ser 337:93-101

Odum EP (1969) The strategy of ecosystem development. Science 164:262-270

Osman RW, Whitlatch RB (1995) The influence of resident adults on larval settlement: experiments with four species of ascidians. J Exp Mar Biol Ecol 190:199-220

Osman RW, Whitlatch RB (2004) The control of the development of a marine benthic community by predation on recruits. J Exp Mar Biol Ecol 311:117-145

Osman RW, Whitlatch RB (2007) Variation in the ability of Didemnum sp. to invade established communities. J Exp Mar Biol Ecol 342:40-53

Perrett LA, Johnston EL, Poore AGB (2006) Impact by association: direct and indirect effects of copper exposure on mobile invertebrate fauna. Mar Ecol Prog Ser 326:195-205

Scheltema RS (1974) Biological interactions determining larval settlement of marine invertebrates. Thalassia Jugosl 10:263-296

Sebens KP, Koehl MAR (1984) Predation on zooplankton by the benthic anthozoans Alcyonium siderium (Alcyonacea) and Metridium senile (Actiniaria) in the New England subtidal. Mar Biol 81:255-271

Stachowicz JJ, Fried H, Osman RW, Whitlatch RB (2002) Biodiversity, invasion resistance, and marine ecosystem function: reconciling pattern and process. Ecology 83: 2575-2590

Editorial responsibility: Hans Heinrich Janssen, Oldendorf/Luhe, Germany
Sutherland JP (1974) Multiple stable points in natural communities. Am Nat 108:859-873

Sutherland JP (1978) Functional roles of Schizoporella and Styela in the fouling community at Beaufort, North Carolina. Ecology 59:257-264

Sutherland JP, Karlson RH (1977) Development and stability or the fouling community at Beaufort, North Carolina. Ecol Monogr 47:425-446

Underwood AJ, Anderson MJ (1994) Seasonal and temporal aspects of recruitment and succession in an intertidal estuarine fouling assemblage. J Mar Biol Assoc UK 74: $563-584$

Wahl M (1985) The recolonization potential of Metridium senile in an area previously depopulated by oxygen deficiency. Oecologia 67:255-259

Wethey DS (1986) Ranking of settlement cues by barnacle larvae: influence of surface contour. Bull Mar Sci 39:393-400

- Whomersley P, Picken GB (2003) Long-term dynamics of fouling communities found on offshore installations in the North Sea. J Mar Biol Assoc UK 83:897-901

- Wieczorek SK, Todd CD (1997) Inhibition and facilitation of bryozoan and ascidian settlement by natural multi-species biofilms: effects of film age and the role of active and passive larval attachment. Mar Biol 128:463-474

> Woolmington $\mathrm{AD}$, Davenport $\mathrm{J}$ (1983) $\mathrm{pH}$ and $\mathrm{PO}_{2}$ levels beneath marine macro-fouling organisms. J Exp Mar Biol Ecol 66:113-124

Young CM (1988) Larval predation by barnacles: effects on patch colonization in a shallow subtidal community. Ecology 69:624-634

> Young CM (1989) Larval depletion by ascidians has little effect on settlement of epifauna. Mar Biol 102:481-489

Young CM, Chia FS (1981) Laboratory evidence for the delay of larval settlement in response to a dominant competitor. Int J Invertebr Reprod 3:221-226

Submitted: October 27, 2009; Accepted: September 22, 2010 Proofs received from author(s): January 6, 2011 